\title{
Atrofia mucosa/translocação bacteriana na sepse experimental em ratos Wistar $^{1}$
}

\author{
Mucosal atrophy/bacterial translocation in experimental sepsis in Wistar rats
}

\author{
Armando José d’Acampora², Daniel Knabben Ortellado ${ }^{3}$, Roberta O. M. Carvalho ${ }^{4}$, João Daniel \\ May Serafim ${ }^{5}$, Débora Cadore de Farias ${ }^{6}$, Ricardo Tramonte ${ }^{7}$
}

1. Trabalho realizado no Núcleo de Pesquisa da Técnica Operatória e Cirurgia Experimental da Universidade Federal de Santa Catarina (TOCE/UFSC).

2. Professor Adjunto, Doutor em Técnica Operatória e Cirurgia Experimental pela Universidade Federal de São Paulo (UNIFESP/EPM). Líder do Grupo de Pesquisa TOCE/UFSC).

3. Médico Residente em Cirurgia de Cabeça e Pescoço do Hospital São Paulo

4. Médica Residente em Radiologia do Hospital Universitário da UFSC.

5. Médico Residente em Cirurgia do Hospital Regional de São José. Santa Catarina.

6. Aluna do Curso de Graduação em Medicina da UFSC.

7. Professor Adjunto, Doutor em Histologia do Núcleo de Pesquisa da TOCE/UFSC.

\section{RESUMO}

OBJETIVO: Avalizar a relação entre lesão mucosa e translocação bacteriana.

MÉTODOS: Utilizou-se 50 ratos distribuídos em 5 grupos: 1.Controle: injeção de inóculo padrão de Pseudomonas aeruginosa, 2.Dreno: injeção do inóculo padrão e drenagem da cavidade abdominal, após 6 horas, 3.Lavado: injeção do inóculo padrão e lavagem da cavidade abdominal, após 6 horas, 4.Lavado + dreno: injeção do inóculo padrão e após 6 horas, drenagem e lavagem da cavidade, 5.Normal: avaliação histológica da parede intestinal normal. Após o óbito, realizou-se hemocultura e cultura peritoneal. Realizouse medida da espessura total da parede do jejuno e da camada mucosa em vilosidades seccionadas de forma longitudinal.

RESULTADOS: Na hemocultura, houve crescimento de Pseudomonas aeruginosa e Escherichia coli em $90 \%$ e 52,5\% dos animais. Na cultura peritoneal, houve crescimento de P. aeruginosa, E. coli e Klebsiella sp em 87,5\%, 85\% e 5\% dos animais. Quanto a altura da camada mucosa e da parede intestinal, não houve alteração estatisticamente significativa entre os 5 grupos.

CONCLUSÃO: A sepse aguda não causou alteração na camada mucosa do intestino delgado e a translocação ocorrida não pode ser considerada como decorrente de uma lesão da mucosa intestinal.

DESCRITORES: Atrofia. Mucosa. Intestino. Translocação.

\begin{abstract}
PURPOSE: Observe the relation between small intestine's mucosal injury and bacterial translocation.

METHODS: 50 adult female rats were distributed in 5 groups: 1 . Control: intraperitoneal injection of Pseudomonas aeruginosa, 2. Drainage: intraperitoneal injection of $P$. aeruginosa and drainage of the
\end{abstract}


abdominal cavity, after 6 hours, 3. Washed: intraperitoneal injection of P. aeruginosa and washing of the abdominal cavity, after 6 hours, 4 . Washed + drainage: intraperitoneal injection of $P$. aeruginosa plus drainage and washing of the cavity, after 6 hours, 5 . Normal: evaluation of the normal intestinal wall.After death, blood and peritoneal cultures were performed. Fragments of jejunum were processed histologically for morphometric measure of the total thickness of the jejujum's wall in comparison to the thickness of the mucosa + submucosa layer.

RESULTS: In blood culture, there was growth of Pseudomonas aeruginosa and Escherichia coli in 90\% and 52,5\% of the animals, respectively. In the peritoneal culture, there was growth of $P$ aeruginosa, E.coli and Klebsiella sp in 87,5\%, 85\% and 5\% of the animals. About the histological analysis and the thickness of the mucosa + submucosa's layer, there was not significant alteration.

CONCLUSION: Acute sepsis did not develop any thickness alteration in the small intestine's mucosa layer. Bacterial translocation can not be a direct consequence produced by mucosal intestinal injury.

KEY WORDS: Atrophy. Mucosal. Intestine. Translocation.

\section{Introdução}

Apesar de todos os avanços no diagnóstico e tratamento da sepse abdominal, a mortalidade continua semelhante àquela de quatro décadas atrás ${ }^{1,2,3,4,5}$. Por outro lado, poucos autores demonstram uma redução considerável na mortalidade da sepse abdominal com o advento de novas formas de tratamento ${ }^{6,7,8}$. A translocação bacteriana corresponde à passagem de bactérias viáveis através da mucosa intestinal até a lâmina própria, e desta para os linfonodos mesentéricos e, possivelmente, para outros tecidos. Essa definição foi posteriormente adaptada, incluindo a passagem de microorganismos ou seus produtos tóxicos (endotoxinas) através da barreira intestinal. Os mecanismos que controlam a translocação bacteriana dependem de múltiplos fatores relacionados ao microrganismo e ao hospedeiro ${ }^{10}$. Dentre esses fatores, talvez um dos mais importantes na fisiopatologia da translocação bacteriana, seja o papel de barreira exercido pela mucosa intestinal. A integridade física da mucosa provavelmente representa a principal linha de defesa dessa barreira intestina ${ }^{11}$, sendo auxiliada pelos componentes do sistema imune celular (enterócitos, macrófagos e linfócitos T) e humoral (IgG, IgM e IgA secretória). Na literatura pesquisada, não foram encontrados trabalhos que esclareçam todas as dúvidas a respeito da influência da sepse no tamanho da mucosa intestinal e da mucosa intestinal na ocorrência de translocação bacteriana.

\section{Métodos}

Amostra

Foram utilizados 50 ratos da espécie Rattus norvergiccus da linhagem Wistar, todos do sexo feminino, com idade média de 120 dias e peso entre 150 e 250 gramas, provenientes do Biotério Central da Universidade Federal de Santa Catarina. Os animais foram distribuídos em 5 subgrupos de 10 animais cada, conforme a descrição a seguir, seguindo o mesma método descrito por d'Acampora:

1) Grupo controle $-\mathbf{C}(\mathbf{n}=\mathbf{1 0})$ : injetou-se um inóculo padrão intraperitonealmente, por via transparietal em 10 ratos. Esses animais foram submetidos a avaliação clínica constante e não receberam nenhum tipo de tratamento.

2) Grupo dreno = D $(\mathbf{n}=\mathbf{1 0})$ : injetou-se um inóculo padrão intraperitonealmente, por via transparietal em 10 ratos. Esses animais foram submetidos a avaliação clínica constante e após 6 horas da inoculação, os animais foram anestesiados de forma padrão. Após a anestesia, foi realizada antissepsia da parede abdominal, laparotomia e drenagem da cavidade abdominal através de um dreno laminar de borracha mole. Após a operação foi realizada observação clínica do animal até o momento do óbito.

3) Grupo lavado - L (n = 10 ): injetou-se um 
inóculo padrão intraperitonealmente, por via transparietal em 10 ratos. Esses animais foram submetidos a avaliação clínica constante e após 6 horas da inoculação, os animais foram anestesiados de forma padrão. Após a anestesia, foi realizada antissepsia da parede abdominal, laparotomia e lavagem da cavidade abdominal com $20 \mathrm{ml}$ de solução aquosa de cloreto de sódio na concentração de $0,9 \%$. Após a operação foi realizada observação clínica do animal até o momento do óbito.

4) Grupo lavado + dreno - LD ( $(n=10)$ : injetou-se um inóculo padrão intraperitonealmente, por via transparietal em 10 ratos. Esses animais foram submetidos a avaliação clínica constante e após 6 horas da inoculação, os animais foram anestesiados de forma padrão. Após a anestesia, foi realizada antissepsia da parede abdominal, laparotomia, lavagem da cavidade abdominal com $20 \mathrm{ml}$ de solução aquosa de cloreto de sódio na concentração de $0,9 \%$ e drenagem da cavidade através de um dreno laminar. Após a operação foi realizada observação clínica do animal até o momento do óbito.

5) Grupo normal - N (n = 10): 10 animais hígidos, os quais não receberam a injeção do inóculo intraperitoneal, foram anestesiados e induzidos à eutanásia para obtenção de amostras de jejuno para avaliação morfométrica de uma parede intestinal normal.

\section{PROCEDIMENTOS}

\section{Procedimento de inoculação}

Para induzir a infecção peritoneal foi utilizado um preparado de bactérias Pseudomonas aeruginosa, na quantidade de $1,2 \times 10^{9}$ bactérias por mililitro. Após anti-sepsia da parede ântero-lateral do abdome com álcool iodado a $2 \%$, introduziu-se $1 \mathrm{ml}$ do inóculo bacteriano para cada $100 \mathrm{~g}$ de peso do animal, via punção abdominal no quadrante inferior esquerdo do abdome.

\section{Procedimento anestésico}

Foi utilizada uma solução de Cetamina ( $5 \mathrm{ml})$ e Xilasina a 2\% (1 ml) sendo injetado $0,5 \mathrm{ml}$ da solução, pela via intramuscular, na face interna da pata traseira direita do animal. O animal foi considerado anestesiado, quando havia perdido o reflexo córneo-palpebral e não exibia qualquer reação motora pela preensão do coxim adiposo de sua pata dianteira.

\section{Procedimento operatório}

Os procedimentos operatórios foram realizados em ambiente propício, seguindo as normas de antissepsia a uma temperatura média de 25 graus centígrados, com auxílio de condicionador de ar. Após 6 horas da inoculação, os animais foram submetidos a anestesia geral, conforme descrito anteriormente. Após a epilação e anti-sepsia em toda a parede anterior e lateral do abdome do animal, com álcool iodado a $2 \%$, foi realizada uma laparotomia mediana de $4 \mathrm{~cm}$. De acordo com o grupo ao qual o animal pertencia, foram realizados diferentes procedimentos. No subgrupo lavado (L), foram introduzidos $20 \mathrm{ml}$ de soro fisiológico $0,9 \%$ na cavidade abdominal e posteriormente aspirados com seringa de $20 \mathrm{ml}$. No subgrupo dreno (D), foi realizada uma incisão de contra-abertura de aproximadamente $1 \mathrm{~cm}$ no flanco esquerdo dos animais. Através desta incisão foi exteriorizado um dreno laminar medindo $5 \mathrm{~cm}$ x 1 $\mathrm{cm}$, e fixado por um ponto com fio monofilamentar de Nylon ${ }^{\circledR}$ 5-0. No subgrupo lavado + dreno (LD), ambos os procedimentos anteriormente descritos foram realizados. Após o procedimento específico para cada grupo, realizou-se a síntese da parede abdominal por planos. Para as camadas peritoneal e muscular, foi utilizado fio de polipropileno 5-0, em chuleio contínuo interrompido a cada quatro pontos. A pele foi suturada com fio monofilamentar de Nylon ${ }^{\circledR}$ 5-0 com pontos simples. Nos animais em que se usou o dreno abdominal, foram utilizados dispositivos tipo "colar cervical”, conforme descrito por Ely PB, d'Acampora AJ, Miltersteiner AR, Hoff FC $^{12}$ com o objetivo de manter a imobilidade da cabeça do animal e, portanto, evitar que o mesmo retirasse o dreno. Os animais foram, posteriormente, acompanhados em sua evolução clínica até o óbito.

\section{Necropsia}

Após o óbito, os animais foram submetidos a incisão tóraco-abdominal, para a realização do inventário das cavidades. Para avaliação histológica, foram retirados fragmentos de intestino delgado de 2 cm de comprimento, num ponto localizado a $5 \mathrm{~cm}$ distalmente ao ângulo de Treitz. Para realização de 
hemocultura, foi colhida uma amostra de $1 \mathrm{ml}$ de sangue intracardíaco sob condições assépticas. Essa amostra foi preservada em meio específico para cultivo de bactérias aeróbias. Para realização da cultura peritoneal, foi colhida amostra de líquido peritoneal da parede antero-lateral esquerda com um swab apropriado e técnica asséptica. O líquido peritoneal foi imediatamente semeado em placas de Petry com meio de cultura de ágar MacConkey. No subgrupo normal, foi realizada apenas anestesia, eutanásia do animal e obtenção de amostra de intestino delgado conforme descrito anteriormente. Os animais que sobreviveram foram submetidos a eutanásia após 48 hs, quando então os mesmos procedimentos acima descritos foram realizados.

\section{Avaliação histológica}

Imediatamente após a necrópsia, as peças retiradas dos animais experimentais foram imersas em solução aquosa de cloreto de sódio a 0,9\% e fixadas em solução de Bouin a 10\%. As peças fixadas foram submetidas ao processo de inclusão em parafina, seguindo a técnica histológica de rotina. Após a inclusão em parafina, as peças de intestino delgado foram seccionadas em micrótomo para obtenção de cortes histológicos de $10 \mu \mathrm{m}$ de espessura segundo um mesmo plano de corte transversal ao sentido da peça. As lâminas assim obtidas foram coradas empregando-se o método da Hematoxilina-Eosina e submetidas a análise morfométrica seguindo os parâmetros propostos por Nascimento e $\mathrm{col}^{13}$ para análises morfométricas em cortes de intestino delgado de ratos. Para o presente trabalho, foi adaptada uma régua ocular ao microscópio óptico que foi calibrada empregando-se uma lâmina objeto, com o objetivo de estipular, em micrômetros (:m), as medidas obtidas. Com a régua ocular, na objetiva de dez vezes, foi realizada a medida da espessura total da parede do intestino delgado e da espessura da camada mucosa e submucosa em uma vilosidade seccionada de forma longitudinal. Apenas vilosidades seccionadas longitudinalmente da sua base até o seu ápice com uma única camada de células epiteliais foram consideradas para avaliação das espessuras do intestino delgado. A medida da espessura total da parede do intestino delgado foi realizada colocando o ponto zero da régua ocular na camada serosa abaixo da vilosidade, medindo-se a espessura até a última camada de células epiteliais em micrômetros, conforme demonstrado na Figura 1. A medida da camada mucosa e submucosa foi realizada colocandose o zero da régua ocular entre as células da camada muscular circular interna e as da submucosa, medindose até a última camada de células epiteliais no ápice da vilosidade.

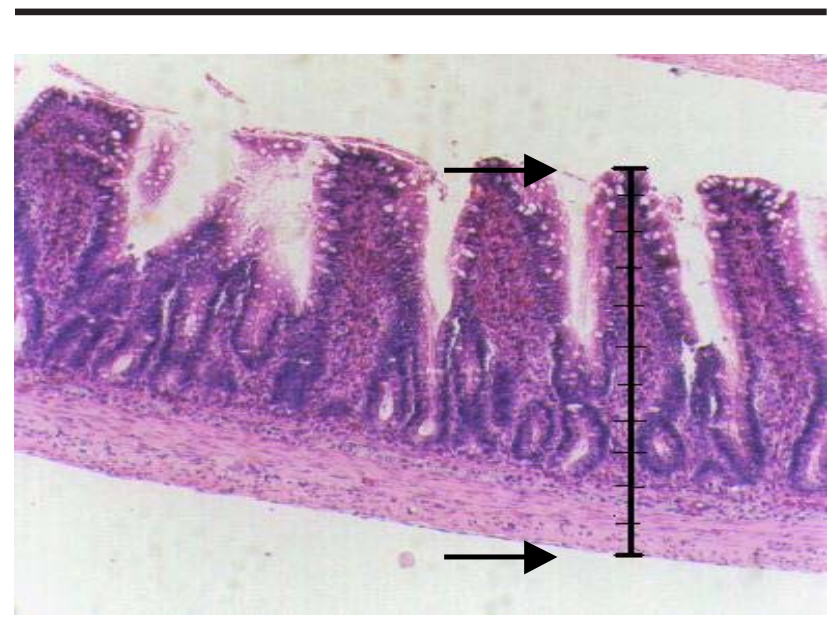

FIGURA 1 - Representação esquemática da mensuração de uma vilosidade da camada serosa até o epitélio (fotomicrografia com objetiva de $10 \mathrm{x}$ ).

Foram realizadas medidas das 3 (três) melhores vilosidades visualizadas, sendo utilizado como resultado, o valor médio dessas medidas.

\section{Avaliação estatística}

Para avaliação da significância estatística dos resultados entre os diferentes grupos foram utilizados os métodos de Análise de Variância (ANOVA) e o teste estatístico de análise de correspondência.

\section{Resultados}

Com os resultados obtidos na mensuração da altura da camada mucosa e da parede total do intestino em três vilosidades diferentes, foi feita a média aritmética entre os valores encontrados e pôde-se avaliar a reação da sepse e das diferentes formas de tratamento sobre a parede intestinal e sobre a camada mucosa. A média das medidas do tamanho da mucosa e da parede intestinal distribuídas entre os diversos grupos pode ser avaliada na Tabela 1.

Quando esses resultados são submetidos ao estudo estatístico de Análise de Variâncias, não se 
identifica diferença estatisticamente significativa entre os grupos $(\mathrm{P}>0,05)$.

O resultado da hemocultura pode ser visualizado na Tabela 2. Dos 40 animais analisados, em 36 deles (90\%) houve crescimento de Pseudomonas aeruginosa na hemocultura e em 21 (52,5\%) houve crescimento de Escherichia coli. A Figura 2 representa graficamente os resultados das hemoculturas encontrados nos 40 animais de experimentação, nos quais foi induzida a sepse.

TABELA 1 - Média do tamanho da mucosa e da parede intestinal em micrômetros distribuídos entre os diferentes grupos experimentais.

\begin{tabular}{lccc}
\hline Grupos & Mucosa $(\mu \mathrm{m})$ & Parede intestinal $(\mu \mathrm{m})$ & Número de ratos \\
\hline C & 385,0 & 488,8 & 8 \\
D & 388,6 & 498,6 & 7 \\
LD & 398,9 & 502,2 & 9 \\
L & 348,9 & 471,1 & 9 \\
N & 396,0 & 481,0 & 10 \\
\hline Total & 383,4 & 488,3 & 43 \\
\hline
\end{tabular}

TABELA 2 - Resultado da hemocultura do sangue intracardíaco nos animais experimentais.

\begin{tabular}{lcccc}
\hline Bactérias & $\begin{array}{c}\text { Positividade } \\
\left(\mathrm{n}^{\circ} \text { de ratos) }\right.\end{array}$ & $\begin{array}{c}\% \text { de } \\
\text { positividade }\end{array}$ & $\begin{array}{c}\text { Negatividade } \\
\left(\mathrm{n}^{\circ} \text { de ratos) }\right.\end{array}$ & $\begin{array}{c}\% \text { de } \\
\text { negatividade }\end{array}$ \\
\hline Pseudomonas aeruginosa & 36 & 90 & 4 & 10 \\
Escherichia coli & 21 & 52,5 & 19 & 47,5 \\
\hline
\end{tabular}

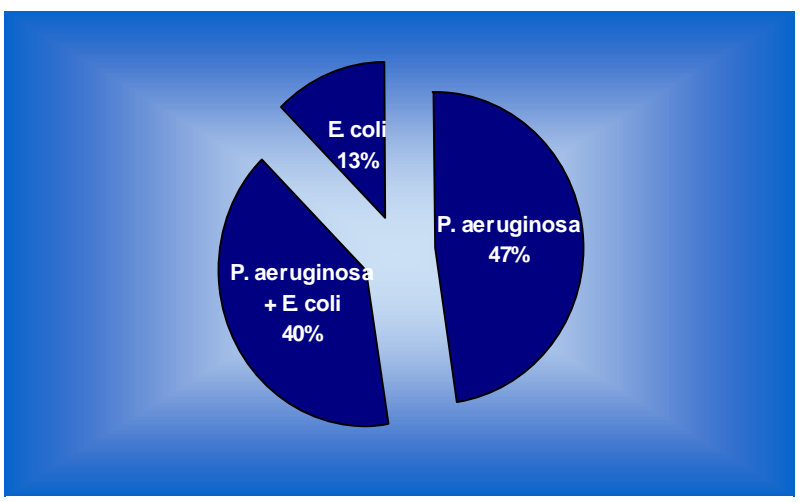

FIGURA 2 - Resultado da hemocultura positiva para Pseudomonas aeruginosa, E. coli ou ambas as bactérias em percentual de positividade.

Na cultura peritoneal houve crescimento de Pseudomonas aeruginosa, Escherichia coli e Klebsiella sp, conforme a distribuição demonstrada na Tabela 3. Em 35 culturas de peritônio (87,5\%) houve crescimento de Pseudomonas aeruginosa, em 34 (85 $\%)$ houve crescimento de Escherichia coli e em 2 culturas (5\%), houve crescimento de Klebsiella sp. A Figura 3 representa graficamente os resultados das culturas peritoneais encontrados nos 40 animais de experimentação nos quais foi induzida a sepse.

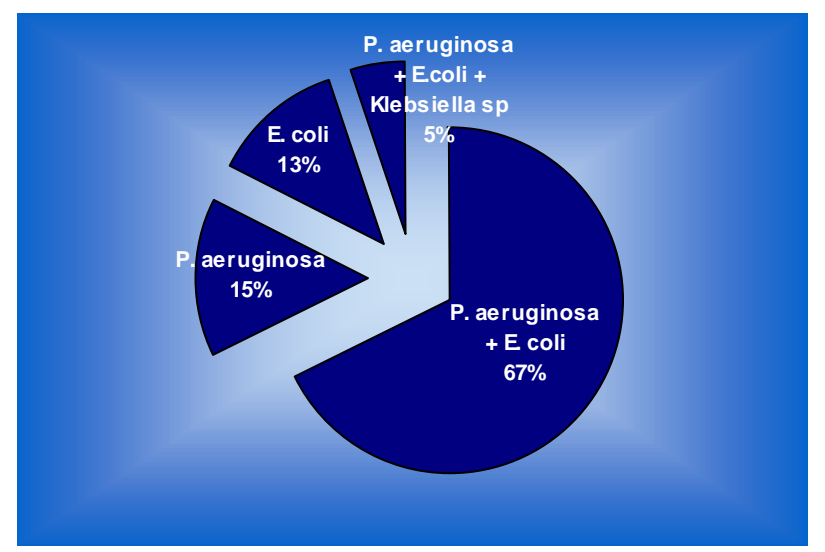

FIGURA 3 - Resultado da cultura peritoneal de acordo com o microorganismo encontrado em percentual de culturas positivas.

Os resultados de hemocultura e cultura peritoneal foram submetidos ao teste estatístico de análise de correspondência, que não mostrou significância estatística $(p>0,05)$ entre os diferentes grupos estudados. Quando comparada a medida das alturas da parede intestinal e da camada mucosa com os achados da hemocultura e cultura peritoneal, não se evidenciou diferença estatisticamente significativa $(p>0,05)$. 
TABELA 3 - Resultado da cultura peritoneal do líquido cavitário colhido nos animais experimentais.

\begin{tabular}{lcccc}
\hline Bactérias & $\begin{array}{c}\text { Positividade } \\
\left(\mathrm{n}^{\circ} \text { de ratos }\right)\end{array}$ & $\begin{array}{c}\% \text { de } \\
\text { positividade }\end{array}$ & $\begin{array}{c}\text { Negatividade } \\
\left(\mathrm{n}^{\circ} \text { de ratos }\right)\end{array}$ & $\begin{array}{c}\% \text { de } \\
\text { negatividade }\end{array}$ \\
\hline P. aeruginosa & 35 & $87,5 \%$ & 5 & $12,5 \%$ \\
Escherichia coli & 34 & $85 \%$ & 6 & $15 \%$ \\
Klebsiella sp & 2 & $5 \%$ & 38 & $95 \%$ \\
\hline
\end{tabular}

\section{Discussão}

Recentemente o trato gastro-intestinal tem assumido maior importância no manuseio e tratamento do paciente séptico. Há bem pouco tempo, o trato gastro-intestinal era considerado um sistema de pouca importância na fisiopatologia da sepse. Acredita-se, atualmente, que o intestino delgado e o colo são responsáveis pela manutenção do hipermetabolismo da sepse, síndrome da resposta inflamatória sistêmica e disfunção de múltiplos órgãos e sistemas ${ }^{14}$, além de serem identificados como um dos alvos primários de lesão na sepse ${ }^{15,16}$. Sob diversas condições nutricionais e patológicas, o intestino pode sofrer atrofia, comprometendo suas funções essenciais ${ }^{17}$. A atrofia pode indicar diminuição da função intestinal de barreira, entretanto isso ainda não foi confirmado em animais de experimentação ${ }^{18}$. Neste estudo foi utilizada a morfometria da parede intestinal para avaliar a atrofia mucosa. A morfometria, quando utilizada para avaliar a atrofia da mucosa do trato gastrointestinal, torna-se um método objetivo com parâmetros quantitativos específicos, e não só qualitativos, apresentando evidência histológica clara de lesão da mucosa. Um dos parâmetros utilizados, é a mensuração da espessura da camada mucosa intestinal, com ênfase para o tamanho das vilosidades. Avaliou-se a apenas a altura da camada mucosa e da parede intestinal do jejuno. Assim como na literatura $^{19,20,21,22}$, no jejuno não houve alterações evidentes na parede intestinal que pudessem ser avaliadas à luz da microscopia óptica. Para avaliar a translocação bacteriana, são utilizados métodos de cultura de diferentes sítios extra-intestinais. Os métodos mais comumente usados na literatura são cultura de líquido peritoneal, cultura de homogeneizado de linfonodos mesentéricos, fígado e baço, cultura de sangue venoso da veia porta e sangue venoso periférico e detecção de endotoxinas no sangue venoso portal e periférico ${ }^{11,23,24,25}$. Como resultado das hemoculturas, foi obtido o crescimento de Pseudomonas aeruginosa em $90 \%$ dos ratos e
Escherichia coli em 52,5\% dos ratos. Na cultura do líquido peritoneal, houve crescimento de Pseudomonas aeruginosa, Escherichia coli e Klebsiella sp no percentual de 87,5\%, 85\% e 5\%, respectivamente, fato também observado por d'Acampora em trabalho anterior ${ }^{16}$. Apesar dos métodos de cultura serem amplamente utilizados na literatura, o isolamento de microorganismos entéricos em sítios extra-intestinais sugere fortemente, mas não prova a translocação bacteriana. Numerosos trabalhos estão sendo realizados com o objetivo de avaliar qual a exata alteração que ocorre na barreira intestinal na presença de uma doença do trato gastrointestinal.A alteração patológica mais frequentemente aventada como causa do defeito na barreira intestinal é a atrofia da mucosa. Entretanto, muitos estudos vem tentando demonstrar a influência de outros fatores, que não a atrofia mucosa, como causa da translocação bacteriana. Brewster e col. ${ }^{26}$ avaliaram a presença de sepse de origem abdominal em crianças desnutridas. Encontraram uma relação direta entre desnutrição e sepse. O autor concluiu que a atrofia das vilosidades e o aumento da celularidade da lâmina própria encontrados nas biópsias de pacientes desnutridos estavam diretamente relacionados com um maior índice de translocação bacteriana e sepse. Nesse caso, a causa da atrofia da mucosa é a diminuição do aporte de nutrientes, principalmente aminoácidos e não uma lesão isquêmica. No presente trabalho não houve redução da oferta de aminoácidos na luz intestinal, o que pode, em parte, manter a integridade da mucosa. Mishima e col. ${ }^{27}$ utilizaram um modelo de endotoxemia induzida por injeção intraperitoneal de lipopolissacarídeo de Escherichia coli em ratos. O trabalho demonstrou que a inibição do óxido nítrico previne isquemia intestinal, causando menos atrofia mucosa e consequentemente menos translocação bacteriana. Gianotti e col. ${ }^{28}$ avaliaram a translocação de Candida albicans através da parede intestinal em grupos de vilosidades com diferentes níveis de perfusão sanguínea. Concluiu que quanto maior o fluxo sanguíneo para as vilosidades, menor a 
lesão que ocorre na mucosa e menor é o índice encontrado de translocação de Candida albicans. Tenenhaus e col..$^{30}$ utilizando um modelo de sepse abdominal em camundongos, avaliaram a influência da câmara hiperbárica com oxigênio a 100\% sobre a morfologia intestinal mucosa e translocação bacteriana. Concluíram que a hiperóxia reduz a isquemia intestinal, protegendo a mucosa e reduzindo os níveis de translocação bacteriana. Os estudos que afirmam não existir relação entre atrofia mucosa e translocação bacteriana, procuram encontrar outros fatores que possam ser responsáveis pela passagem de bactérias da luz intestinal para a circulação sistêmica. Os fatores mais comumente aventados como causa de translocação bacteriana nesses trabalhos incluem alterações na microflora intestinal, alterações no sistema imune do hospedeiro, alterações químicas e físicas do muco intestinal e da mucina e alterações da aderência bacteriana à mucosa do trato gastro-intestinal ${ }^{11,31}$. Katayama e col. ${ }^{31}$ compararam a lesão mucosa intestinal e a translocação bacteriana em dois grupos experimentais de ratos: um grupo foi submetido a desnutrição protéica e outro a endotoxemia com lipopolissacarídeo de Escherichia coli. No grupo submetido a desnutrição protéica, foi encontrada lesão de maior intensidade na mucosa do intestino delgado e pouca translocação bacteriana. No grupo submetido a endotoxemia, foi encontrada pouca intensidade de lesão mucosa e uma grande quantidade de translocação bacteriana. $\mathrm{O}$ autor concluiu que a atrofia mucosa e a barreira intestinal contra ascensão de microorganismos não estão necessariamente relacionadas e outros fatores devem estar envolvidos na barreira intestinal biológica. McCauley e col. ${ }^{9}$ estudaram o efeito da nutrição enteral mínima em ratos submetidos a nutrição parenteral total (NPT). A nutrição enteral mínima em ratos sob NPT pareceu reduzir a extensão da atrofia mucosa, quando comparados com ratos que não receberam nutrição enteral mínima. Entretanto, essa diferença não afetou a incidência de translocação bacteriana. Foi concluído que não há relação entre atrofia mucosa por NPT e incidência de translocação bacteriana. Na literatura consultada, apenas um estudo associou tamanho da mucosa e translocação bacteriana em humanos. Foram avaliadas as alturas da superfície mucosa em biópsias de 58 pacientes, não encontrando diferença entre pacientes com e sem translocação bacteriana ${ }^{32}$. No presente trabalho, não houve diferença entre os tamanhos das paredes intestinais e das mucosas entre os diversos grupos. Nesse caso, pode-se afirmar que a sepse não causou alterações visualizáveis à microscopia óptica na mucosa intestinal. Considerando os resultados da análise morfométrica da parede do jejuno, não se pode afirmar que os achados das culturas sejam decorrentes de uma lesão na parede intestinal. Neste caso, deve haver outros fatores, além da atrofia mucosa, que propiciem ou facilitem a translocação bacteriana. A hipótese da relação entre translocação bacteriana e aumento da permeabilidade intestinal por lesão mucosa ainda não esta definida, assim com não está completamente definida a relação entre a translocação bacteriana e a disfunção de múltiplos órgãos e sistemas. Mais estudos são necessários para avaliar essas relações, visto que futuramente, a prevenção da translocação bacteriana pode fazer parte do arsenal terapêutico do paciente séptico. Essa forma de tratamento teria como objetivo reduzir a ocorrência de complicações infecciosas e de disfunção de múltiplos órgãos e sistemas em pacientes gravemente enfermos.

\section{Conclusões}

1. A sepse aguda não causou alteração na parede intestinal ou na camada mucosa do intestino delgado.

2. A translocação ocorrida não pode ser considerada como decorrente de uma lesão da mucosa intestinal.

\section{Referências}

1. Doberneck RC, Mittelman J. Reappraisal of the problems of intra-abdominal abscess. Surg Gynecol Obstet 1982, 154:875-9.

2. Steinberg D. On leaving the peritoneal cavity open in acute generalized suppurative peritonitis. Am J Surg 1979, 137: 216-20.

3. Leiboff AR, Soroff HS. The treatment of generalized peritonitis by closed postoperative peritoneal lavage. Arch Surg 1987, 122: 1005-10.

4. Pitcher WD, Musher DM. Critical importance of early diagnosis and treatment of intra-abdominal infection. Arch Surg 1982, 117: 328-33.

5. Marik, P.E.; Varon, J. The hemodynamic derangements in sepsis: implications for treatment strategies. Chest 1998, 114(3): 854-60.

6. Hunt JL. Generalized peritonitis. Arch Surg 1982, 117: 209-11.

7. Bohnen JMA, Mustard RA. A critical look at scheduled 
relaparotomy for secondary bacterial peritonitis. Surg Gynecol Obstet 1993, 172: 25-9.

8. Buanes TA, Gunnar PA, Ulf J, Knut N. Perforated appendicitis with generalized peritonitis. Eur J Surg 1991, 157:277-9.

9. McCauley RD, Heel KA, Christiansen KJ, Hall JC. The effect of minimum luminal nutrition on bacterial translocation and atrophy of the jejunum during parenteral nutrition. J Gastroenterol Hepatol 1996, 11(1): 65-70.

10. Wells CL, Maddaus MA, Simmons RL. Proposed mechanisms for the translocation of intestinal bacteria. Rev Infect Dis 1988, 10: 958-79.

11. Kazantsev GB, Hecht DW, Rao R, Fedorak IJ et al. Plasmid labeling confirms bacterial translocation in pancreatitis. Am J Surg 1994, 167(1): 201-7.

12. Ely PB, d'Acampora AJ, Miltersteiner AR, Hoff FC. Dispositivo do tipo colar cervical para proteção de ferida operatória abdominal em ratos. Acta Cir Bras 1997, 12( Supl. 2): S15-6.

13. Nascimento AJE, Silva LRF, Oliveira AF, Silva MHG. Enhanced mucosal re-epithelization induced by short chain fatty acids in experimental colitis. Braz J Med Biol Res 1999, 32(8): 961-6.

14. Deitch EA. Multiple organ failure. Pathophysiology and potencial future therapy. Ann Surg 1992; 216: 117-34.

15. Duranteau J, Sitbon P, Teboul JL, Vicaut E, Anguel N, Richard C, et al. Effects of epinephrine, norepinephrine, or the combination of norepinephrine and dobutamine on gastric mucosa in septic shock. Crit Care Med 1999; 27(5):893-900.

16. d'Acampora AJ. Modelo de sepse experimental em ratos: estudo clínico e histológico [Tese]. Universidade Federal de São Paulo - Escola Paulista de Medicina; 1996.

17. Baracos VE, Samuels SE, Adegoke OAJ. Anabolic and catabolic mediators of intestinal protein turnover: a new experimental approach. Curr Opin Clin Nutr Metab Care 2000; 3(3): 183-9.

18. Deitch EA. Bacterial translocation of the gut flora. J Trauma 1990; 30: 184-9.

19. Yassin MMI, Barros AAB, Parks TG, McCaigue, MD, Leggett P, Halliday MI, et al. Lower limb ischaemiareperfusion injury alters gastrointestinal structure and function. Br J Surg 1997, 84(10): 1425-9.

20. Farges MC, Raul F, Cezard JP, Davot P, Meunier MT, Cynober L, et al. A pancreatic extract-enriched diet corrects ileal mucosa atrophy in endotoxemic aged rats.
Dig Dis Sci 1998, 43(10): 2244-50.

21. Naka S, Saito H, Hashiguchi Y, Lin MT, Furakawa S, Inaba $\mathrm{T}$ et al. Alanylglutamine-enriched total parenteral nutrition improves protein metabolism more than branched chain amino acid-enriched total parenteral nutrition in protracted peritonitis. J Trauma 1997, 42(2): 183-90.

22. Alpers DH. Is glutamine a unique fuel for small intestinal cells? Curr Opin Gastroenterol 2000, 16(2): 155.

23. Lemaire, LCJM, Van Lanschot JJB, Stoutenbeek CP, Van Deventer SJH, Wells CL, Gouma DJ. Bacterial translocation in multiple organ failure: cause or epiphenomenon still unproven. Br J Surg 1997, 84(10): 1340-50.

24. Kale TI, Kuzu MA, Tekeli A, Tank A, Aksoy M, Cete M. Agressive bowel preparation does not enhance bacterial translocation, provided the mucosal barrier is not disrupted: A prospective, randomized study. Dis Colon Rectum 1998, 41(5): 636-41.

25. Sodeyama M, Gardiner KR, Regan MC, Kirk SJ, Efron G, Barbul A. Scientific papers: sepsis impairs gut amino acid absorption. Am J Surg 1993, 165(1): 150-4.

26. Brewster D, Manary M, Menzies I, O’Loughlin EV, Henry RL. Intestinal permeability in kwashiorkor. Arch Dis Child 1997, 76(3): 236-41.

27. Mishima S, Xu D, Lu Q, Deitch EA. The relationships among nitric oxide production, bacterial translocation, and intestinal injury after endotoxin challenge in vivo. $\mathrm{J}$ Trauma 1998, 44(1): 175-82.

28. Gianotti L, Alexander JW, Fukushima R, Childress C. Translocation of Candida albicans is related to the blood flow of individual intestinal villi. Circ Shock 1993, 40:2507.

29. Tenenhaus M, Hansbrough JF, Zapata-Sirvent R, Neumann T. Treatment of burned mice with hyperbaric oxygen reduces mesenteric bacteria but not pulmonary neutrophil deposition. Arch Surg 1994, 129: 1338-42.

30. Gennari R, Alexander JW. Effects of hyperoxia on bacterial translocation and mortality during gut-derived sepsis. Arch Surg 1996, 131(1): 57-62.

31. Katayama M, Xu D, Specian R, Deitch EA. Role of bacterial adherence and the mucus barrier on bacterial translocation: Effects of protein malnutrition and endotoxin in rats. Ann Surg 1997, 225(3): 317-26.

32. Sedman PC, MacFie J, Palmer MD, Mitchell CJ, Sagar PM. Preoperative total parenteral nutrition is not associated with mucosal atrophy or bacterial translocation in humans. Br J Surg 1995, 82(12):1663-7.

Correspondência:

Armando José d'Acampora

Condomínio San Diego, casa 9

88034-420 Florianópolis - SC

acampora@ccs.ufsc.br

Recebimento: 15/04/2004

Revisão: 20/05/2004

Aprovação: 17/06/2004 
d'Acampora AJ e col

Conflito de interesse: nenhum

Fonte de financiamento: nenhuma

\section{Como citar este artigo:}

d'Acampora AJ, Ortellado DK, Carvalho ROM, Serafim JDM, Farias DC, Tramonte R. Atrofia mucosa/translocação bacteriana na sepse experimental em ratos Wistar. Acta Cir Bras [serial online] 2004 Set-Out;19(5). Disponível em URL: http://www.scielo.br/acb [também em CD-ROM].

* Figuras coloridas disponíveis em www.scielo.br/acb 